US performed in radiology were $4 \%, 0.7 \%$ referred by the respiratory teams and the rest mainly from intensive care.

No major complication (death, organ injury, empyema, bleeding) occurred. All specialist registrars reached level 1 US.

Conclusion A dedicated mid-week pleural procedures session improved the training and supervision for respiratory trainees and provides a safe service.

This session reduced the burden of procedures performed on Mondays but was not sufficient to reduce the numbers performed before the weekend. An additional session is planned for Fridays.

A level 1 thoracic US trained ANP assisted the training of juniors and the provision of service.

Most pleural US and procedures are performed on the pleural unit, which reduced the burden on radiology department.

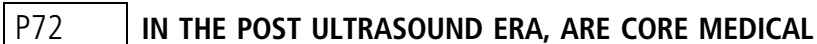 TRAINEES STRUGGLING TO GET EXPERIENCE IN CHEST DRAIN INSERTION?}

JL Connor, P Griffiths, M Gautam, A Youzguin; Southport District General Hospital, Southport, United Kingdom

\subsection{6/thoraxjnl-2013-204457.222}

Introduction In the UK, upon completion of Core Medical Training (CMT), procedural independence is expected for pneumothorax drains and is desirable for pleural effusions. In 2009, prompted by a National Patient Safety Agency report, a local guideline was introduced in our hospital aiming to reduce intercostal chest drain (ICD) complications for effusions by formalising training, increasing supervision and utilising bedside ultrasound scan (USS). Consequently, rates of adverse events have significantly been reduced. This raises the question, however, have such measures reduced the procedural exposure for CMT doctors.

We aimed to compare the numbers of ICDs inserted by CMT doctors for effusions in 2008 and 2012. The numbers of ICDs inserted by CMTs for pneumothorax compared to effusion in 2012 was also examined.

Methods All patients who received an ICD for effusion or pneumothorax in 2012 and for effusion in 2008 were retrospectively reviewed. We reviewed grade of doctor performing ICD insertion, supervision, and use of USS (for effusion).

Results CMTs inserted significantly less ICDs for effusions in $2012(10 / 30,33 \%)$ compared to $2008(20 / 39,51 \%) \mathrm{z}=1.75$, $\mathrm{p}=0.04$. Supervision rates increased from $73 \%$ in 2008 to $100 \%$ in 2012 . Bedside USS was used in $100 \%$ of effusionrelated ICDs in 2012 compared to $0 \%$ in 2008.

In 2012 alone, CMTs inserted significantly fewer ICDs for pneumothorax $(4 / 28,14 \%)$ compared to effusions $(10 / 30,33 \%) \mathrm{z}=$ $1.69, \mathrm{p}=0.046$. A\&E doctors inserted the majority of ICDs for pneumothorax $(15 / 28,53 \%)$, whilst a Respiratory Registrar/Consultant inserted the majority of ICDs for effusions (13/30, 43\%).

Conclusions Since 2008, there has been a significant reduction in ICD insertions by CMTs. The majority of ICD insertions for pleural effusions being performed using USS by appropriately trained respiratory physicians may explain this. The significant fall in the number of ICD insertions by CMTs for pneumothorax (where USS guidance is not required) however, suggests that overall ICDs are becoming a specialist procedure rather than a generic competency. Trainees are at risk of not fulfilling their competency requirements and this poses the question should procedural training and curriculum objectives be readdressed in light of the growing need for USS experience.

\section{P73 THE CREATION OF A SIMULATED PAN-DEANERY MEDICAL THORACOSCOPY AND INDWELLING PLEURAL CATHETER COURSE}

${ }^{1} \mathrm{~F}$ Chowdhury, ${ }^{2} \mathrm{~N}$ Chaudhuri, ${ }^{3} \mathrm{~S}$ Renshaw, ${ }^{1} \mathrm{~S}$ Pathmanathan, ${ }^{4} \mathrm{~J} \mathrm{Hogg,}{ }^{3} \mathrm{~J}$ Hill, ${ }^{4} \mathrm{P}$ Blaxill, ${ }^{5}$ T Rogers, ${ }^{1} \mathrm{~J}$ Kastelik; ${ }^{1}$ Hull Institute of Learning and Simulation, Hull, East Yorkshire; ${ }^{2}$ United Hospitals of South Manchester, Manchester, UK; ${ }^{3}$ Sheffield Teaching Hospitals NHS Foundation Trust, Sheffield, South Yorkshire; ${ }^{4}$ Pinderfields Hospital NHS Trust, Wakefield, UK; ${ }^{5}$ Doncaster and Bassetlaw Hospitals NHS Trust, Doncaster, UK

\subsection{6/thoraxjn-2013-204457.223}

Introduction Medical thoracoscopy (MT) and indwelling pleural catheter (IPC) insertion are becoming increasingly utilised for the purposes of diagnostic and therapeutic intervention in pleural disease. We are at the cusp of a paradigm shift towards the expansion of hospital services within Respiratory departments nationally, to accommodate the ever increasing demand of advances in medical treatment. Few courses are available that train respiratory doctors nationally. Health Education Yorkshire and The Humber have designed a novel simulation course to teach trainees the skills of MT and IPC insertion.

Methods A respiratory simulation team involving three consultants and a registrar used an approach similar to that described by Tjiam et al. 2012 using a cognitive task analysis (CTA) and the four component instructural design (4C/ID) as the basis of the course. The blueprint was created which broke down the tasks involved. The course consisted of four lectures and a demonstration followed by four stations including medical thoracoscopy; trocar and chest drain insertion; IPC insertion and a multiple choice questionnaire (MCQ). Peer review of the lectures and also the MCQ was also carried out. All consultants from specialist lung cancer services across the region were invited to be faculty on the course. Pre and post course Likert scale questionnaires were used to assess confidence levels.

Results Statistically significant improvements in confidence levels were achieved in all 8 domains, particularly in technical ability

\begin{tabular}{|c|c|c|c|c|}
\hline Confidence levels in: & $\begin{array}{l}\text { Number } \\
\text { of } \\
\text { trainees }\end{array}$ & $\begin{array}{l}\text { Mean } \\
\text { Improvement } \\
\text { (SD) }\end{array}$ & $\begin{array}{l}\% \\
\text { Improvement }\end{array}$ & $\begin{array}{l}P \\
\text { Value }\end{array}$ \\
\hline $\begin{array}{l}\text { Knowing the indications } \\
\text { for thoracoscopy }\end{array}$ & $\begin{array}{l}\text { Pre=11, } \\
\text { Post=11 }\end{array}$ & $1.27(0.65)$ & 31.82 & 0.004 \\
\hline $\begin{array}{l}\text { Knowing the } \\
\text { contra-indications for } \\
\text { thoracoscopy }\end{array}$ & $\begin{array}{l}\text { Pre=11, } \\
\text { Post=11 }\end{array}$ & $1.36(0.67)$ & 34.09 & 0.004 \\
\hline $\begin{array}{l}\text { Consenting the patient } \\
\text { and quoting accurate } \\
\text { complication rates }\end{array}$ & $\begin{array}{l}\text { Pre }=11 \\
\text { Post }=11\end{array}$ & $1.36(0.5)$ & 34.09 & 0.002 \\
\hline $\begin{array}{l}\text { Being aware of the } \\
\text { complications of } \\
\text { thoracoscopy }\end{array}$ & $\begin{array}{l}\text { Pre }=10 \\
\text { Post }=11\end{array}$ & $1.3(0.67)$ & 32.50 & 0.006 \\
\hline $\begin{array}{l}\text { Knowing the limits of } \\
\text { safe conscious sedation } \\
\text { and the complications }\end{array}$ & $\begin{array}{l}\text { Pre }=11 \\
\text { Post }=11\end{array}$ & $1.54(0.93)$ & 38.64 & 0.004 \\
\hline $\begin{array}{l}\text { Technical ability in handling } \\
\text { the thoracoscopy equipment }\end{array}$ & $\begin{array}{l}\text { Pre }=11 \\
\text { Post }=11\end{array}$ & $2.54(0.82)$ & 63.64 & 0.004 \\
\hline $\begin{array}{l}\text { Knowing the indications } \\
\text { for IPC insertion }\end{array}$ & $\begin{array}{l}\text { Pre=10, } \\
\text { Post=11 }\end{array}$ & $2.1(1.1)$ & 52.50 & 0.007 \\
\hline $\begin{array}{l}\text { Technical ability in } \\
\text { performing an IPC insertion }\end{array}$ & $\begin{array}{l}\text { Pre }=11 \\
\text { Post }=11\end{array}$ & $2.45(1.69)$ & 61.36 & 0.007 \\
\hline
\end{tabular}


in handling the thoracoscopy equipment and IPC insertion (figure 1). $100 \%$ of consultants agreed that the course was mapped to the respiratory curriculum requirements and that the content was appropriate for ST5 trainees. 100\% of consultant faculty also agreed that the course structure was adequate; the lectures were delivered at an appropriate level and were happy for the course to be run on a yearly basis. Candidate feedback was positive and indicated that the course would be a useful addition to the training programme.

Conclusion With medical advancements and expansion of Lung Cancer Services nationwide, respiratory doctors are increasingly needed to master MT and IPC insertion skills. Intra-deanery training should be provided for trainees to ensure sustainability of services.

\section{P74 EXPERIENCES OF A SIMULATED PLEURAL BIOPSY TRAINING COURSE FOR RESPIRATORY REGISTRARS IN A HIGH TUBERCULOSIS INCIDENCE REGION OF THE UK}

${ }^{1}$ WM Ricketts, ${ }^{1} \mathrm{M}$ Farrugia, ${ }^{2} \mathrm{~J}$ Goldring, ${ }^{1} \mathrm{~T}$ O'Shaughnessy, ${ }^{3} \mathrm{M}$ Sheaff, ${ }^{4} \mathrm{DT}$ McLeod; ${ }^{1}$ Newham University Hospital, Barts Health NHS Trust, London, UK; ${ }^{2}$ Royal Free London NHS Foundation Trust, London, UK; ${ }^{3}$ Royal London Hospital, Barts Health NHS Trust, London, UK; ${ }^{4}$ Sandwell and Birmingham NHS Trust, Birmingham, UK

\subsection{6/thoraxjnl-2013-204457.224}

Introduction and Objectives Last year we presented data highlighting the on-going role for Abrams pleural biopsy in areas with high tuberculosis incidence (1). Feedback reiterated ongoing need, but highlighted concerns regarding the attainment of trainee competence at this infrequently performed procedure. We organised and evaluated a half day training course using a well validated porcine-resin model at a regional registrar training day (2).

Methods All attendees (18) underwent a practical training session on pleural biopsy using Abrams and Tru-Cut biopsy needles. Feedback forms were completed and perceived success documented, all samples obtained underwent histological assessment by a specialist respiratory Consultant Histopathologist.

Results Previous experience was limited (median 0.5 prior biopsies performed, range 0-50). On Likert scales (range 1-5) mean confidence improved (1.86, SD 1.21 to 3.83 , SD 0.51 ; p < 0.0001 ) and the session was deemed useful (mean score 4.5, SD $0.4)$ with $13 / 14(92.9 \%)$ trainees who answered stating the session would change their practice. A mean of 4.56 samples (SD 1.42) were obtained per trainee. Sixty-nine of seventy-six samples $(90.8 \%)$ were perceived to have been successful by the operator, microscopic evidence of mesothelial lined pleura was obtained in nine samples $(11.8 \%)$ with connective tissue suggestive of possible pleura obtained in a further 25 (33\%) $(\kappa=0.013$; poor correlation); real time observation by a training partner suggested a $91.9 \%$ success rate $(\kappa=0.584$; moderate correlation). There was no increase in accuracy with increased sampling. Despite encouragement only four participants attempted the Tru-Cut method.

Conclusions The session was popular and significantly improved trainee confidence. However, histological biopsy success rate and macroscopic correlation was poor. This is most likely related to difficulty in biopsying non-diseased pleura and possibly differences between macroscopic appearances of porcine and human pleura or inexperienced trainees' inability to recognise pleura macroscopically. Experience was low even in a high-incidence region, suggesting simulated pleural biopsy training may be a useful adjunct.

\section{REFERENCES}

1. Brown J et al. Abrams-Needle Pleural Biopsy Remains a Useful Investigation in Suspected Pleural Tuberculosis. Thorax 2012;67(Suppl 2):A113-A113.

2. Naicker TR et al. Validation of a novel resin-porcine thorax model for chest drain insertion training. Clinical medicine 2012;12:49-52.

\section{P75 PULMONARY PHYSIOGICAL TESTS: TRAINEES EXPERIENCE AND EXPOSURE}

${ }^{1} \mathrm{H}$ Lockman, ${ }^{2} \mathrm{NJ}$ Bell; ${ }^{1}$ Universiti Sains Islam Malaysia, Kuala Lumpur, Malaysia; ${ }^{2}$ Bristol Royal Infirmary, Bristol, United Kingdom

\subsection{6/thoraxjnl-2013-204457.225}

Introduction Knowledge of pulmonary function test (PFT) is essential for every respiratory physician. The level of training and exposure to PFT varies depending on the local facilities, supervisors and the respiratory trainees themselves. Moreover in recently cardio-pulmonary exercise testing (CPET) are becoming more widely available as well.

Objectives

1. To test the knowledge of UK respiratory physicians (trainees mainly) on PFT and CPET, identifying what is available locally.

2. The level of exposure to the tests themselves in terms of how to perform, the process involved and the equipment used/ available locally.

Methodology An electronic survey was distributed to the UK postgraduate deaneries for all the respiratory trainees and also to some respiratory physicians, thoracic surgeons and lung function physiologists. Feedback was collected anonymously over a period of 6 months (Dec 2012-May 2013). The questions ranged from simple spirometry, PFT, CPET and basic demographics.

Results A total of 160 responses were obtained from 16 deaneries out of 20 [ 1 from outside the UK - OOPE]. 83 (53\%) were respiratory specialist/specialty registrars and 61(39\%) consultants.

2 respondents had never seen spirometry performed, and 28 (18\%) have not seen a PFT performed. Only $1 / 4$ have done a PFT themselves. 70\% have seen CPET, 29\% have done CPET, $75 \%$ have a CPET service locally with cycle ergometer (66\%) being the most common method to exercise the patient. Respiratory physiologists and respiratory physicians are the ones mainly reporting CPET results with anaesthetist a distant third.

Summary Most trainees have been exposed to spirometry but based on this survey almost $20 \%$ have yet to see a PFT performed. Understanding the process of how to do a PFT and CPET, experiencing it personally could influence the number of PFT requests. This aspect of respiratory specialty training is still insufficient based on the feedback of respiratory trainees who answered this survey.

\section{P76 INVESTIGATING WOMEN'S EXPERIENCES OF ASTHMA CARE IN PREGNACY: A QUALITATIVE STUDY}

${ }^{1} \mathrm{C}$ Chamberlain, ${ }^{2} \mathrm{G}$ R Williamson, ${ }^{1} \mathrm{~B}$ Knight, ${ }^{1} \mathrm{M}$ Daley, ${ }^{1} \mathrm{DM}$ Halpin; ${ }^{1} R D \& E$ NHS Foundation Trust, Exeter, UK; ${ }^{2}$ Plymouth University, Plymouth, UK

\subsection{6/thoraxjnl-2013-204457.226}

Introduction and objectives Most asthmatic women have normal pregnancies and complications are infrequent when their asthma is controlled (BTS/SIGN 2012). Symptom control and medical treatment concern them, as does the impact of their illness and treatment on their unborn baby (Lim et al 2012). Few qualitative studies illustrate recently delivered asthmatic mothers' feelings about their care, support and medication during their pregnancy. 